\title{
Factors Influencing Sand Re-liquefaction in Shaking Table Test
}

\author{
Dikshit Babu Nepal a, Jianliang Deng ${ }^{b}$, Jinjian Chen ${ }^{c}$, Prakriti Pokhrel ${ }^{d}$ \\ a, b, c State Key Laboratory of Ocean Engineering, Department of Civil Engineering, \\ Shanghai Jiao Tong University, Shanghai 200240, China \\ b Masters Research Scholar, Pokhara University, Nepal \\ Corresponding Email: b dengjianliang@sjtu.edu.cn
}

\begin{abstract}
Cases of historical earthquakes show that liquefied sand deposits may undergo re-liquefaction yet again by a succeeding earthquake. However various factors such as the depth of sand deposits, peak ground acceleration, and shaking duration of an earthquake can affect the re-liquefaction occurrence. To understand this underlying mechanism, a series of shaking table experiments were performed by varying the depth of sand model, peak ground acceleration, and shaking duration of input motion. The excess pore water pressure and the acceleration response of the sandy model in the process of re-liquefaction in the sand were measured. The test result demonstrated that during a subsequent re-liquefaction, shear wave propagation mechanism and the number of times sand re-liquefy varies with the depth of sand model suggesting that the re-liquefaction resistance is depth-dependent, and the soil layer near the surface is most likely to be liquefied. The analysis by varying peak ground acceleration and shaking duration of input motion indicated that the model subjected to shorter duration and higher peak ground acceleration of input motion have a greater tendency to re-liquefy in multiple number of shaking, signifying that the conventional strategy for liquefaction resistance needs to be improved before it can be implemented for the analysis of site liquefaction. Based on the findings of parametric studies, there exists a critical liquefaction void ratio within a zone with which we can forecast the presence or absence of liquefaction in the future earthquakes.
\end{abstract}

\section{Keywords}

Re-liquefaction, Shake table, EPWP, Liquefaction resistance, PGA

\section{Introduction}

A well-known known example of severe liquefaction damaged structures and agricultural lands was visible during the earthquake (Magnitude 7.7) which occurred in the Tohoku district of Japan on May 26, 1983 (Tohno and Shamoto, 1986). Similar damage was caused in liquefaction triggered by an aftershock (magnitude 7.1) about a month later in the same area (Tohno and Shamoto, 1986) and Yasuda and Tohno (1988). Several case studies and reconnaissance (Huang and Yu, 2013), (Papathanassiou et al., 2005), (Youd and Hoose, 1978), Kuribayashi and Tatsuoka (1975), Wakamatsu (2012), and Sims and Garvin (1995) illustrated that sand deposits once liquefied might again liquefy in the future by a subsequent earthquake with a similar or even smaller energies than the previous one which is a very alarming issue.

Ishihara and Okada (1978) and Suzuki and Toki (1984) examined the re-liquefaction resistance of the sand using triaxial test and established that the sand easily re-liquefies despite the increase in density. Destruction of aged soil structures by large shear straining makes the liquefied sand act as a fresh deposit following a post-liquefaction consolidation which may reduce the post shaking liquefaction resistance (Olson et al., 2005). Ha et al. (2011), Ye and $\mathrm{Hu}$ (2018), and Babu Nepal et al. (2020) also concluded that the re-liquefaction resistance of sand decreases during the second shaking and starts increasing after it. Ye et al. (2018) after studying the mesoscopic structure of sand explained that the only decrease in the re-liquefaction resistance in the second event is because the horizontal long-axis direction of the sand particle during the virgin state changes to vertical (decreasing the re-liquefaction resistance) and continues to stay vertical afterward making the effect of density a dominating factor to affect re-liquefaction phenomenon after the second liquefaction. In this regard, the site once liquefied is considered 
susceptible to re-liquefaction in the future earthquake.

To examine the effect of peak ground acceleration (PGA), Ayoubi and Pak (2017) conducted centrifugal tests and found out that the increase in PGA has an increasing effect on both excess pore water pressure ratio $\left(r_{u}\right)$ and settlement. Toyota and Takada (2017) conducted a triaxial test to approximate the ratio of liquefaction strength for the duration of and afterward liquefaction using samples with past data of over consolidation. Despite having an increase in liquefaction strength, the shear wave velocity measurement is seen to be unaffected by stress history. Ye and $\mathrm{Hu}$ (2018) concluded that the pore pressure generation is influenced by permeability and the settlement is higher in looser sand and it decreases with the increase in density. Arulandan and Sybico Jr (1992) stated the reason for significant settlement after liquefaction to be the rise in permeability as they discovered that the permeability of sand rises afterward the point of initial liquefaction. Apart from the results obtained, Ecemis (2013) studied the quality and reliability of measured data conducted using the laminar box and shaking table. Ladd (1977) and Mulilis et al. (1977) performed cyclic triaxial tests and stated the way of sample preparation can meaningfully affect the cyclic performance of sands, and this consequence is most likely for inconsistencies in the sand fabrics.

The prime parameters that researchers consider checking the status of liquefaction/re-liquefaction are excess pore pressure $\left(u_{x}^{\prime}\right)$, settlement $(\delta)$ and the maximum excess pore water pressure ratio $\left(r_{u}=u_{x} / \sigma_{v o}^{\prime}\right)$, where, $\sigma_{v o}^{\prime}$ is the initial vertical effective stress. However, these factors are affected by several factor such as the shaking duration, PGA and thickness/depth of sand layers, etc. This study is concentrated on the effects of these factors on the EPWP ratio.

\section{Experimental Modeling and Methodology}

The sand model experiment was performed in the shaking table (Capacity: Max acceleration of 1G; Max displacement of $\pm 125 \mathrm{~mm}$; Frequency that can be generated being $0.150 \mathrm{~Hz}$ ) as shown in Figure 1 . The grain size distribution of yellow sand (locally available in China) was observed to be within the liquefiable range as reported by Tsuchida (1970) and was thus used for the shake table experiment (Figure
2). The index properties are listed in Babu Nepal et al. (2020).

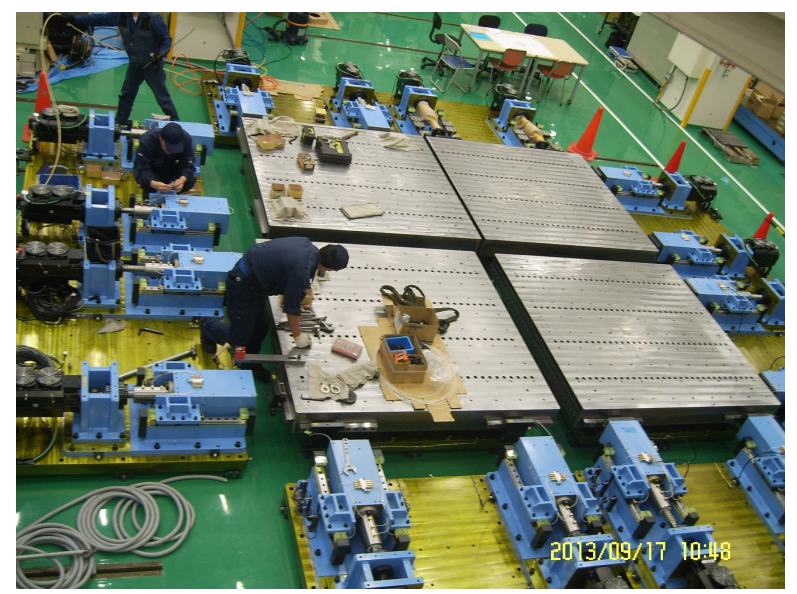

Figure 1: Shaking table used for the experiment

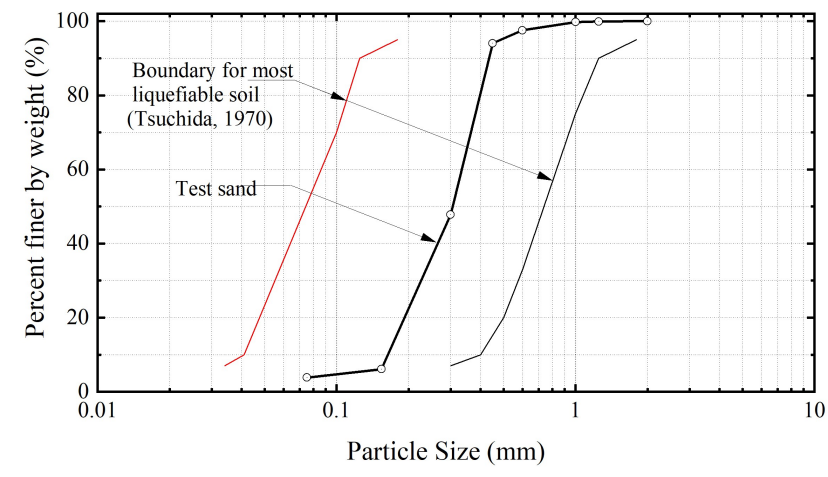

Figure 2: Grain size distribution of experimental sand

Three model boxes with internal dimension $27.7 \mathrm{~cm}$ (length) $\times 27.7 \mathrm{~cm}$ (width) $\times 40 \mathrm{~cm}$ (height) were designed and fabricated for the shake table and were merged as shown in Figure 3 to study the effects of depth and thickness of sand model for the same applied earthquake. The model had three units namely: separated thick unit; unseparated thick unit; and thin unit respectively. The separated thick unit had a layer of separation between the sand layers at 10 $\mathrm{cm}$ intervals. The separation of layer was done by an impermeable thin membrane as shown in Figure 4. The separated and unseparated units were filled with sand up to $30 \mathrm{~cm}$ depth while the thin unit was filled with $10 \mathrm{~cm}$ of sand. Based on this model preparations, the first model acts as a thick sand model with three thin separated layers, the second model acts as a thick sand model with a single layer and the third model acts as a thin sand model.

Seven pore water transducers $\left(P_{1}-P_{7}\right)$ and eight accelerometers were fixed in their respective positions. Seven accelerometers $\left(A_{1}-A_{7}\right)$ were buried in the 


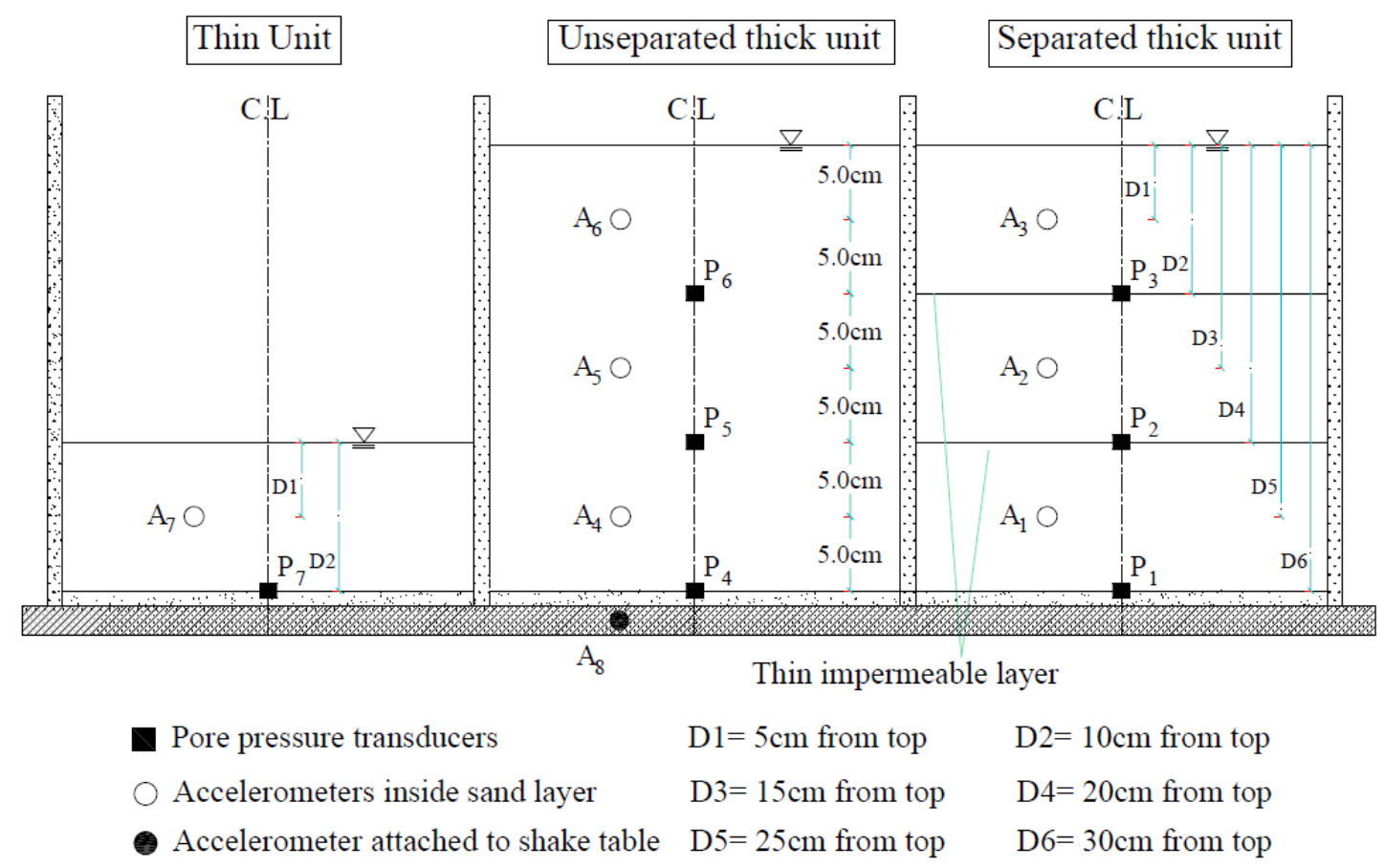

Figure 3: Schematic model and instrumentation layout for the sand model

sand, while one accelerometer $\left(A_{8}\right)$ was set on the shaking table near the base of the model to measure the input acceleration. The detailed explanation of the sensor position is as explained in Table 1. The accelerometers are placed at random positions to decrease the concentration of voids over the central area. The experimental arrangements with the position of sensors are as shown in Figure 3. During that period, a scale was attached to the model box to check the cumulative settlement data for each test. The water content, void ratio, and degree of saturation of the thus prepared sample were calculated based on the cumulative settlement of sand. During the experiment, all the model box was filled with water, and oven-dried sand was allowed to fall from a narrow tip funnel (the mass of dry sand and the water used were measured in advance) so that the sand lies above the prior sand particles by gravity.In the case of separated thick model with layer separation, an impermeable layer was cast in each $10 \mathrm{~cm}$ height. The surface was leveled and the excess water at the surface was removed by siphoning without disturbing the sample. Then, the model was left for 24 hours saturation.

A total of 3 sets of tests for 9 models of soil samples were performed to examine the liquefaction manners of the sandy soil model. In every examination, all three arranged ground were shaken numerous times consecutively. The successive shaking for each test was performed only after the EPWP generated were completely dissipated. The settlement of the ground was noted in advance and afterward of each shaking event. The differences and variations in input acceleration are shown in Figure 5 while the input loading conditions of all the tests performed are summarized in Table 2.

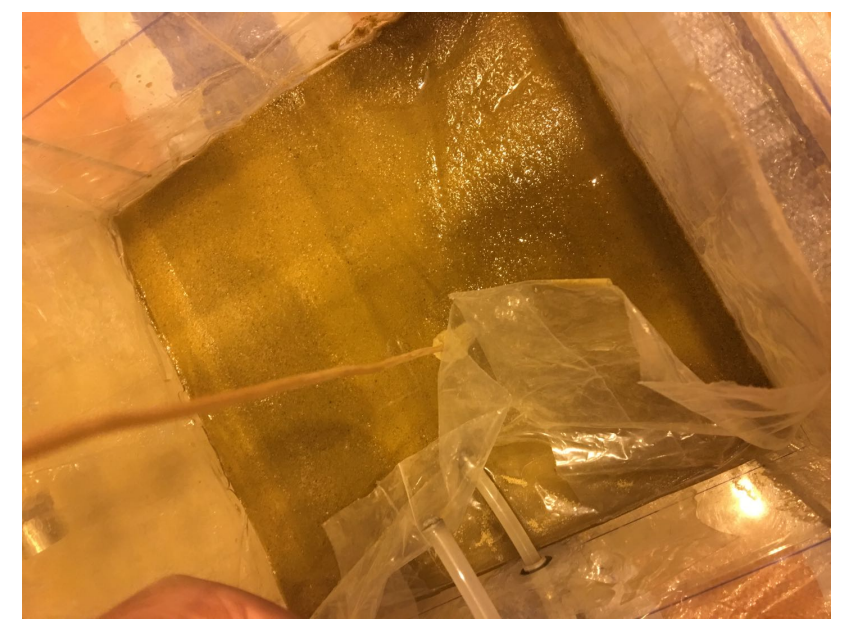

Figure 4: Layer separation during model preparation

\section{Results}

Liquefaction occurs when EPWP $\left(\Delta_{u x}\right)$ reaches the initial vertical effective stress $(\sigma)_{v o}^{\prime}$, i.e., excess pore water pressure ratio $\left(r_{u}=\Delta_{u x} / \sigma_{v o}^{\prime}\right)$ is unity. The trend 
Table 1: Notations used for data analysis

\begin{tabular}{ccc}
\hline Notation & Description & Sensor \\
\hline$D 6_{\text {separated-thick }}$ & $30 \mathrm{~cm}$ of sand from top in seperated thick unit model & $P_{1}$ \\
$D 4_{\text {separated-thick }}$ & $20 \mathrm{~cm}$ of sand from top in seperated thick unit model & $P_{2}$ \\
$D 2_{\text {separated-thick }}$ & $10 \mathrm{~cm}$ of sand from top in seperated thick unit model & $P_{3}$ \\
$D 6_{\text {unseparated-thick }}$ & $30 \mathrm{~cm}$ of sand from top in unseperated thick unit model & $P_{4}$ \\
$D 4_{\text {unseparated-thick }}$ & $20 \mathrm{~cm}$ of sand from top in unseperated thick unit model & $P_{5}$ \\
$D 2_{\text {unseparated-thick }}$ & $10 \mathrm{~cm}$ of sand from top in unseperated thick unit model & $P_{6}$ \\
$D 2_{\text {thin }}$ & $10 \mathrm{~cm}$ of sand from top in thin unit model & $P_{7}$ \\
$D 5_{\text {separated-thick }}$ & $25 \mathrm{~cm}$ of sand from top in seperated thick unit model & $A_{1}$ \\
$D 3_{\text {separated-thick }}$ & $15 \mathrm{~cm}$ of sand from top in seperated thick unit model & $A_{2}$ \\
$D 1_{\text {separated-thick }}$ & $5 \mathrm{~cm}$ of sand from top in seperated thick unit model & $A_{3}$ \\
$D 5_{\text {unseparated-thick }}$ & $25 \mathrm{~cm}$ of sand from top in unseperated thick unit model & $A_{4}$ \\
$D 3_{\text {unseparated-thick }}$ & $15 \mathrm{~cm}$ of sand from top in unseperated thick unit model & $A_{5}$ \\
$D 1_{\text {unseparated-thick }}$ & $5 \mathrm{~cm}$ of sand from top in unseperated thick unit model & $A_{6}$ \\
$D 1_{\text {thin }}$ & $5 \mathrm{~cm}$ of sand from top in thin unit model & $A_{7}$ \\
\hline
\end{tabular}

Table 2: Summary of all tests performed

\begin{tabular}{ccccc}
\hline Test & Model No. & Duration of shaking & PGA & Sand model type \\
\hline 1 & 1 & $3 \mathrm{sec}$ & $0.15 \mathrm{~g}$ & Separated thick \\
1 & 2 & & & Unseparated thick \\
& 3 & & & Thin \\
& 4 & $6 \mathrm{sec}$ & $10.23 \mathrm{~g}$ & Separated thick \\
2 & 5 & & & Unseparated thick \\
& 6 & $3 \mathrm{sec}$ & $0.35 \mathrm{~g}$ & Thin \\
& 7 & & & Separated thick \\
3 & 9 & & & Unseparated thick \\
& 9 & & & Thin \\
\hline
\end{tabular}

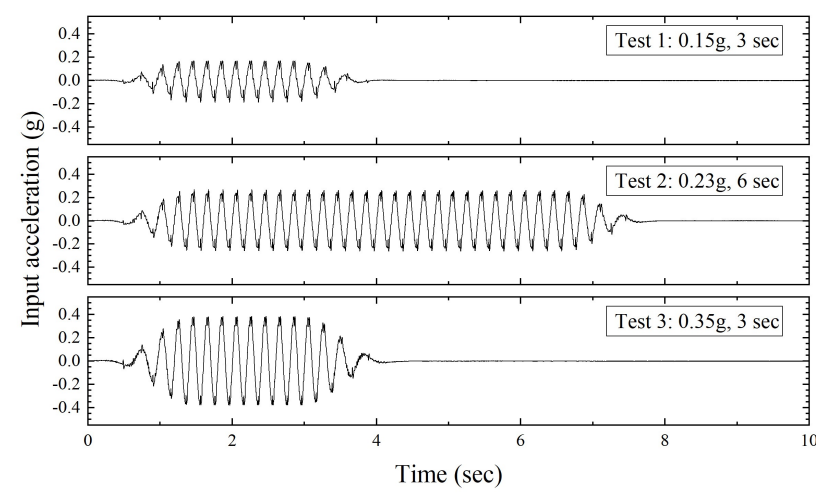

Figure 5: Acceleration time history of input motion

of $\Delta_{u x}$ for all tests was converted to an equivalent value of $r_{u}$ to carry out further analysis.

\subsection{Effects of PGA of input motion on PWP response}

Figure 6 shows the variation of $r_{u}$ calculated based on EPWP measured by pore water transducers $P_{3}, P_{6}$, and
$P_{7}$ for all 3 shaking events. $P_{3}, P_{6}$, and $P_{7}$ measures the pore water response for $D 2_{\text {separated-thick, }}$,

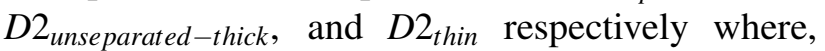
$D 2_{\text {unseparated-thick }}, D 2_{\text {separated-thick }}$, and $D 2_{\text {thin }}$ are the index used for different sand models as explained in Table 1. The input shaking duration for test 1 and 3 were the same (i.e. $3 \mathrm{sec}$ ) as shown in Figure 5. Thus, the variation of $r_{u}$ in all three sand models for all shaking events in test 1 was compared to the corresponding values in test 3 to study the effect of PGA of input motion on re-liquefaction behavior (Figure 6). In test 1 with $0.15 \mathrm{~g}$ as PGA of input

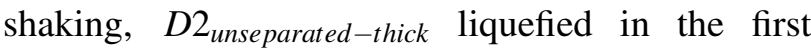
trembling event while $D 2_{\text {thin }}$ and $D 2_{\text {separated-thick }}$ sand model did not liquefy in any of the shaking. But, in test 3 where the PGA of input shaking was $0.35 \mathrm{~g}$, $D 2_{\text {separated-thick, }} \quad D 2_{\text {unseparated-thick, and } D 2_{\text {thin }}}$ liquefied in three, four, and two consecutive shaking events respectively. Moreover, for non-liquefied events in all models, the value of $r_{u}$ for shaking events having higher PGA in input motion was high. The 
lower EPWP buildup and early fall of the value of $r_{u}$ towards zero in test-1 are due to lower PGA of input motion that generates less EPWP.

\subsection{Effects of shaking duration of input motion on PWP response}

The input shaking duration for test 2 was $6 \mathrm{sec}$ as shown in Figure 5. Thus, the variation of $r_{u}$ in sand models for all shaking events in test 1 was compared to the corresponding values in test 2 to study the effect of shaking duration on pore-water pressure ratio (Figure 7). In test 1 where the PGA of input shaking was $0.15 \mathrm{~g}$ and shaking duration was $3 \mathrm{sec}$, none of the $D 2_{\text {separated-thick }}$ and $D 2_{\text {thin }}$ liquefied in any shaking event. But in test 2, where the PGA of input shaking was $0.23 \mathrm{~g}$ and shaking duration was $6 \mathrm{sec}$, both $D 2_{\text {separated-thick }}$ and $D 2_{\text {thin }}$ liquefied once. If we only look at the mechanisms described here above, it could be because of higher PGA input motion in test 2 which liquefies the sand. But, with the event progression, $r_{u}$ in test- 1 is higher than in test- 2 . Also, $r_{u}$ for $D 2_{\text {thin }}$ significantly reduces to 0.15 in the $4^{\text {th }}$ shaking event while the corresponding values of $r_{u}$ in test 1 is higher than that in test 2. (i.e. 0.3). A similar mechanism is observed for $D 2_{\text {separated-thick }}$ and $D 2_{\text {unseparated-thick }}$ sand models. Initial higher value in $r_{u}$ but a significant reduction in the value of $r_{u}$ in test 2 compared to 1 is observed because longer shaking duration which let the EPWP fall quickly.

This mechanism can be explained referring to Figure 8 as well. It is observed that the EPWP in first shaking event was able to maintain at the liquefied height for 6 seconds until the input motion ceased. In the second event, EPWP rose to $100 \%$ and the decline of EPWP appeared after it makes the EPWP in later part of the second shaking event unable to liquefy. The EPWP built up in the third shaking event was only up to the position from where the dissipation started after the input shaking was ceased in second shaking. This signifies that, had an input motion of a longer duration than 6 seconds was subjected, even the second event would not get liquefied in the earlier part. Extending this phenomenon, the EPWP can even decay to zero in the first shaking only if the duration is too long.

\subsection{Effects of thickness and depth of sand model on PWP response}

To explain the phenomenon in a clearer picture, the EPWP generated in pore water transducers $P_{6}, P_{3}$, and $P_{7}$ for the first three shaking events are shown in
Figure 8, Figure 9 and, Figure 10 respectively. All the models in Figure 8, Figure 9 and, Figure 10 of test- 2 are subjected to input motion of the same PGA and duration. To find the effect of depth and thickness of sand model in re-liquefaction of sand, the value of $r_{u}$ calculated based on EPWP measured by pore water transducers $P_{3}, P_{6}$ and $P_{7}$ for all shaking events is presented in Figure 11 and Figure 12. The EPWP generated for the $D 2_{\text {separated-thick }}$ and $D 2_{\text {thin }}$ sand models decay at the later period in the first shaking event making the PWP ratio less than 1 in the subsequent events. On the other hand, the EPWP generated for $D 2_{\text {unseparated-thick }}$ sand model continues to liquefy in the second event as well. This phenomenon can be clarified as follows. For the first shaking event in virgin sand with the same relative density, it is observed that the EPWP generated for $D 2_{\text {separated-thick }}$ sand model is comparatively less or it decays earlier even if it has the same EPWP. This is because the shear wave propagation mechanism measured at $D 2_{\text {separated-thick }}$ is different from that with $D 2_{\text {unseparated-thick }}$ and $D 2_{\text {thin }}$ as shown in Figure 13. The shear wave cycles measured at $D 1_{\text {unseparated-thick }}$ are larger in comparison to $D 1_{\text {separated-thick. }}$ Moreover, these motions at $D 1_{\text {separated-thick attenuates significantly in }}$ comparison to the motion at $D 1_{\text {unseparated-thick. }}$. In test 3 where sand liquefied multiple times because of higher PGA and lower shaking duration,

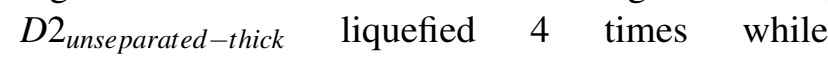
$D 2_{\text {separated-thick }}$ only thrice as shown in Figure 11. $D 2_{\text {thin }}$ with the same height liquefied only twice as shown in Figure 12. Apart from this, in the cases where the sand model did not liquefy as well, the EPWP generated in $D 2_{\text {unseparated-thick }}$ was always higher than that in $D 2_{\text {separated-thick }}$ and $D 2_{\text {thin }}$ sand model. This phenomenon appeared to be true for all tests performed. This occurrence can be described as follows: In the shaking progression after the first event, the re-liquefaction mechanism is governed by the increase in relative density with depth. After the input shaking stops, the sand particles begin to sink. In the case of $D 2_{\text {separated-thick, }}$, the sand particles near to the base of $D 2_{\text {separated-thick }}$ sinks to the base of that layer (i.e. D2), and the upper particles fall on it. While in the case of $D 2_{\text {unseparated-thick }}$ sand model, the sand particles near the base of the $D 2_{\text {unseparated-thick }}$ sinks to the base of the whole model (i.e. D6), and upper particles falls above it. Similarly, in the $D 2_{\text {thin }}$ sand model, the sand particles near the base of $D 2_{\text {thin }}$ sinks to the base of the $D 2_{\text {thin }}$ 

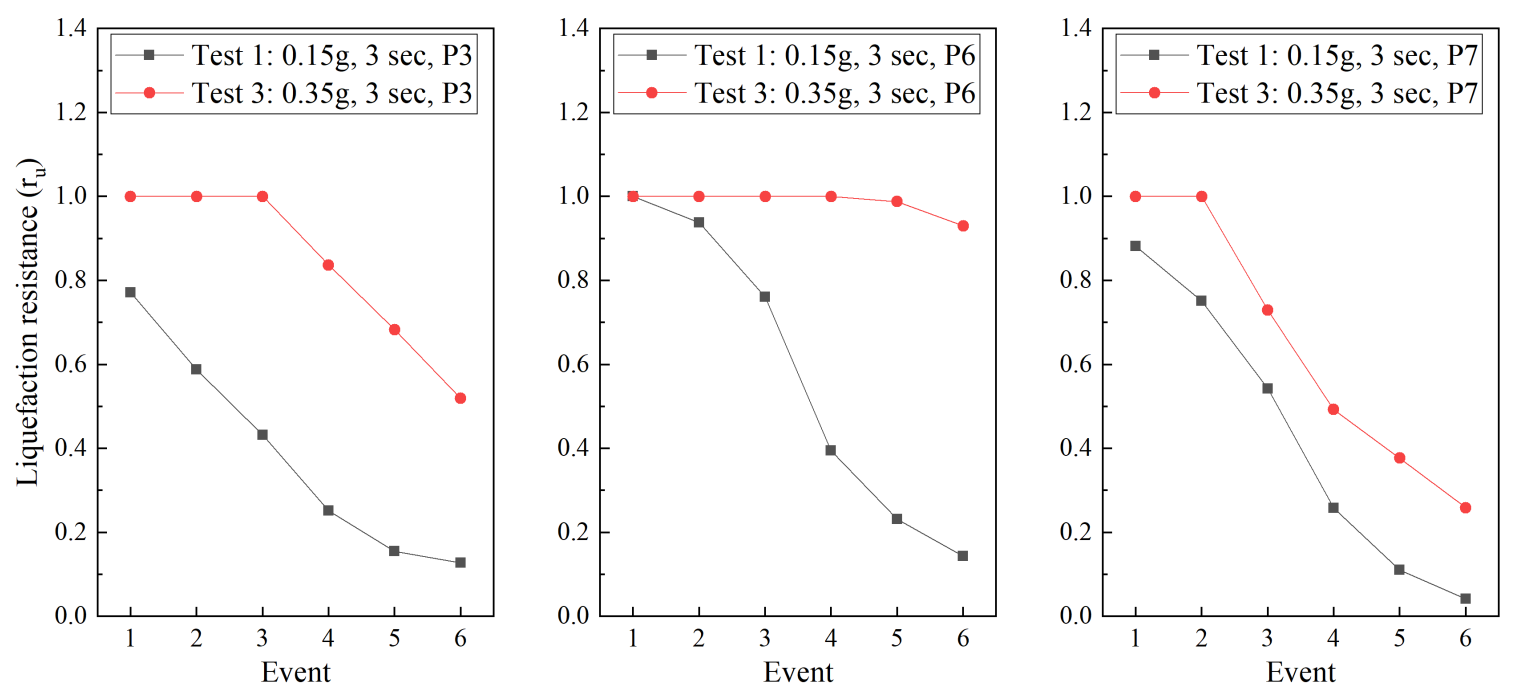

Figure 6: Variation of $r_{u}$ with PGA of input motion
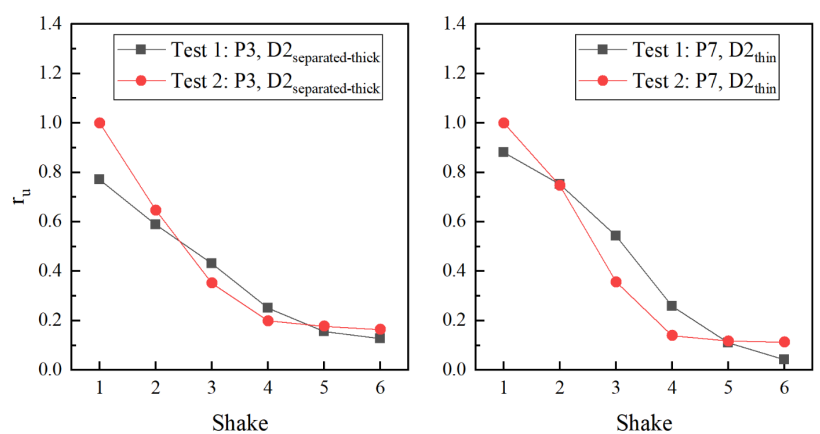

Figure 7: Variation of $r_{u}$ with duration of input motion

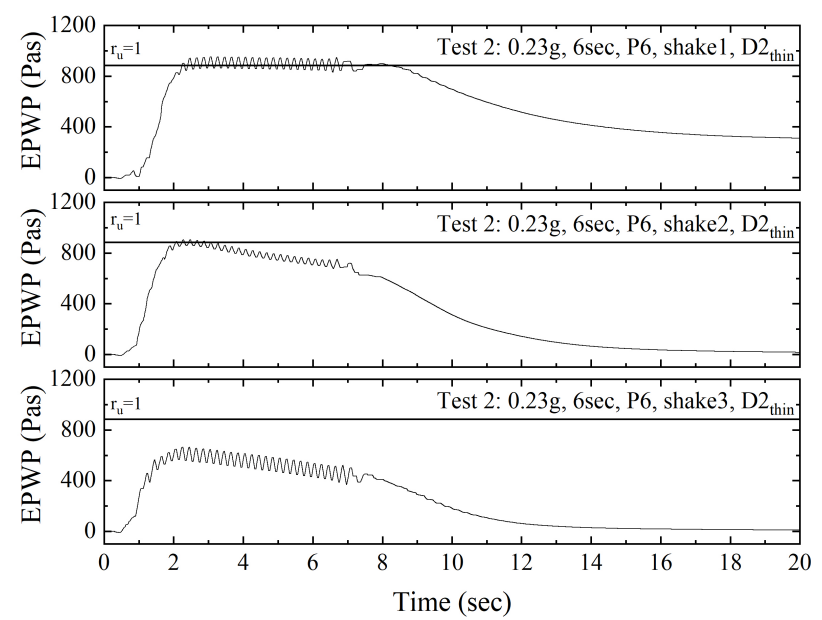

Figure 8: PWP response in $D 2_{\text {unseparated-thick }}$

sand model after the input motion ceases. Thus, in the case of the $D 2_{\text {unseparated-thick, the relative density of }}$ sand increases towards the base (i.e. D6). Consequently, $D 2_{\text {unseparated-thick }}$ sand model becomes looser and more susceptible to re-liquefaction in comparison to $D 2_{\text {separated-thick }}$ and $D 2_{\text {thin }}$ sand

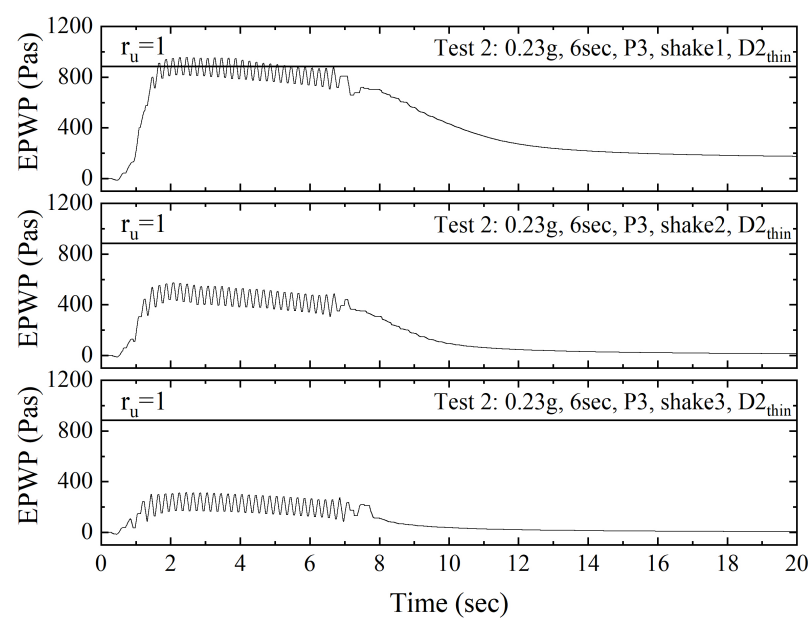

Figure 9: PWP response in $D 2_{\text {separated-thick }}$

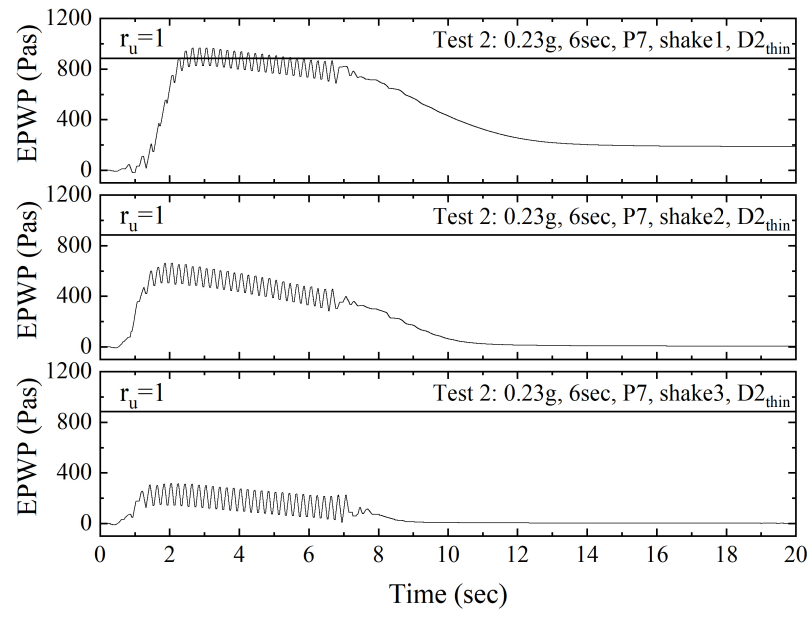

Figure 10: PWP response in $D 2_{\text {thin }}$

model. 

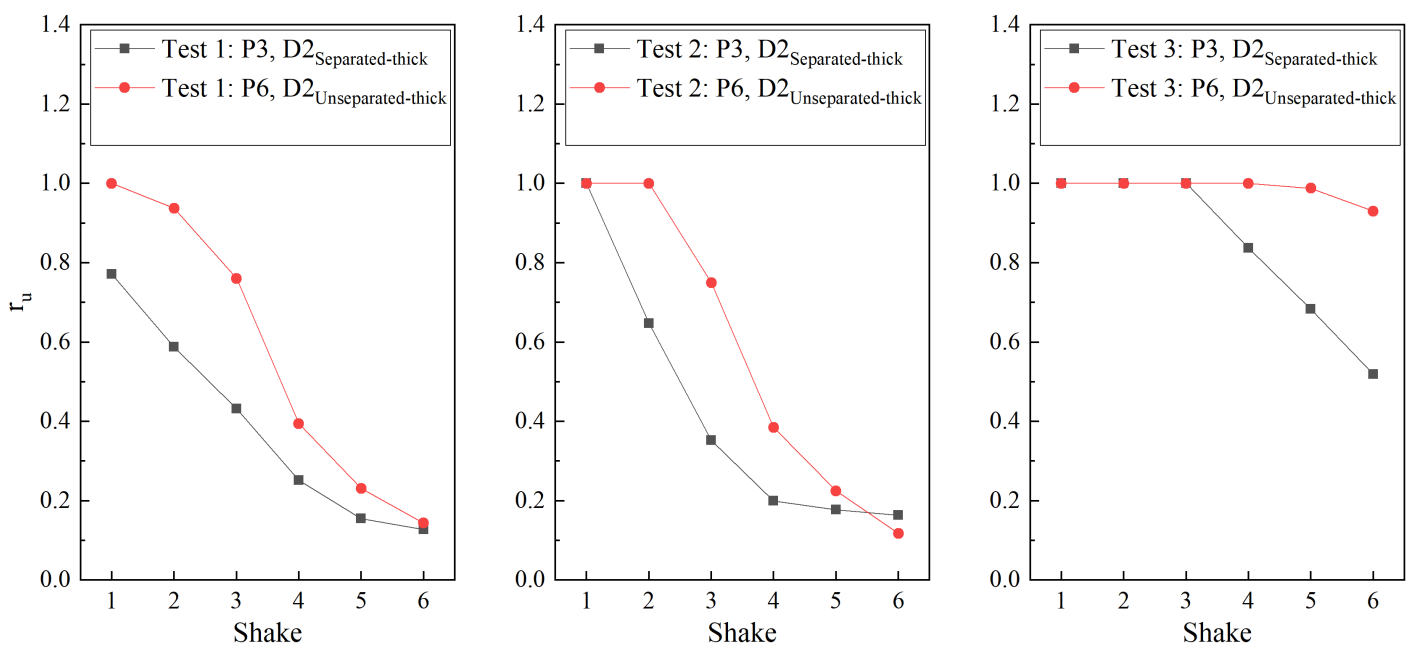

Figure 11: Variation of $r_{u}$ with thickness of sand
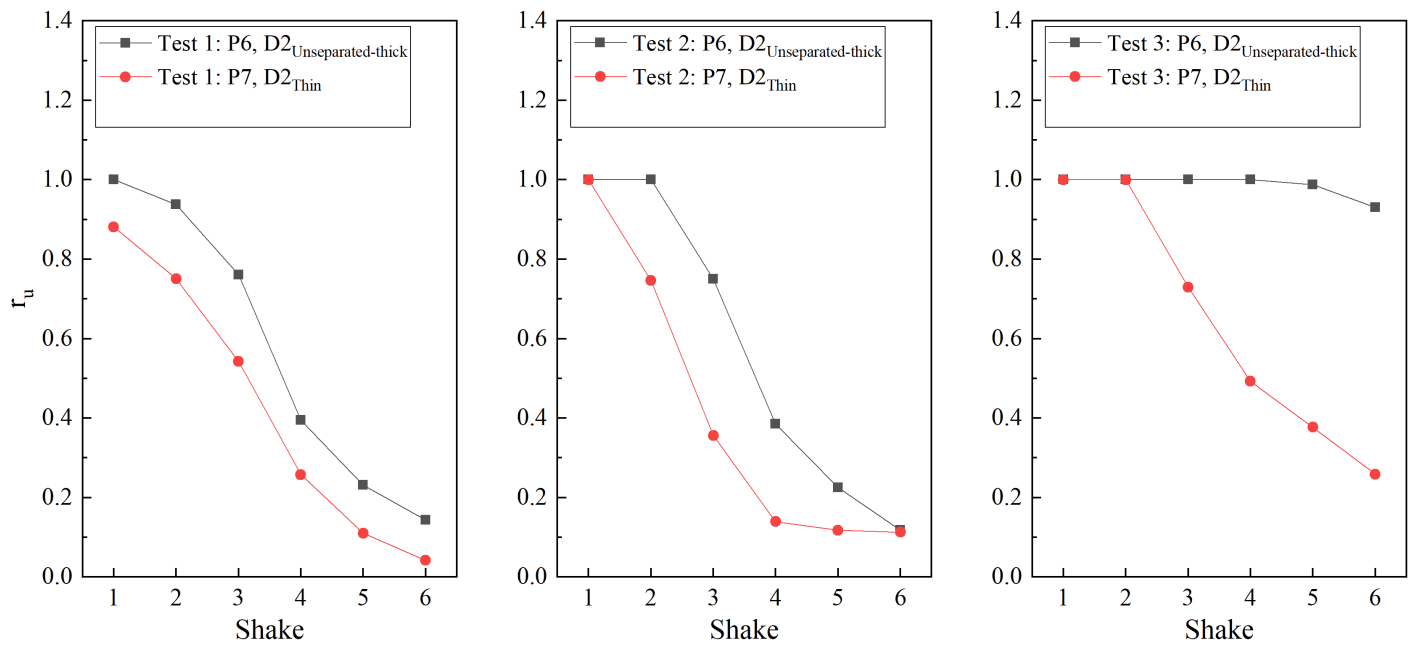

Figure 12: Variation of $r_{u}$ with depth of sand response

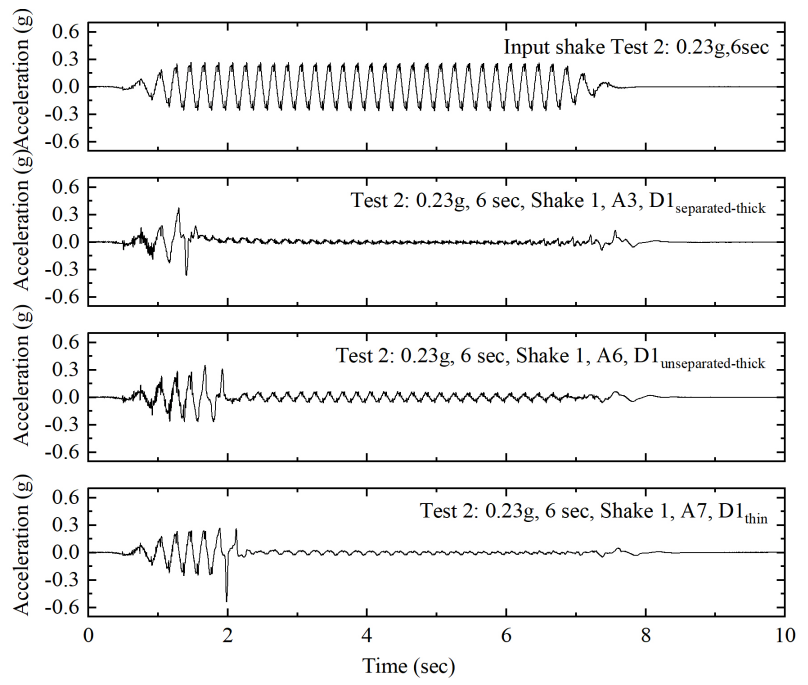

Figure 13: Acceleration response in test 2

\section{Discussion}

Based on all the test performed, the liquefied and non-liquefied models were examined based on the pre-event void ratio as shown in Figure 14. The hollow and filled points signify that the model liquefied and didn't liquefy in that shaking event, respectively. It is observed that $D 2_{\text {thin }}$ in test- 3 could not liquefy after the void ratio falls below 0.68 but the sand of equivalent height $D 2_{\text {unseperated-thick }}$ liquefied until the pre-event void ratio was 0.64. Similarly, for the same duration of input motion in test $1, D 2_{\text {thin }}$ sand did not liquefy at all but $D 2_{\text {unseperated-thick }}$ liquefied until the pre-event void ratio did not fall below 0.76 . Thus, there exists a critical liquefaction void ratio (CLVR) within a zone denoted by two horizontal lines in Figure 14 after which the sand could not liquefy for that particular PGA of input motion and height of the sand model. The CLVR zone can be formed smaller out of many trial experiments. Based on these horizontal lines, the following conditions can be derived: (1) CLVR can change depending on the PGA of input earthquake. In other 

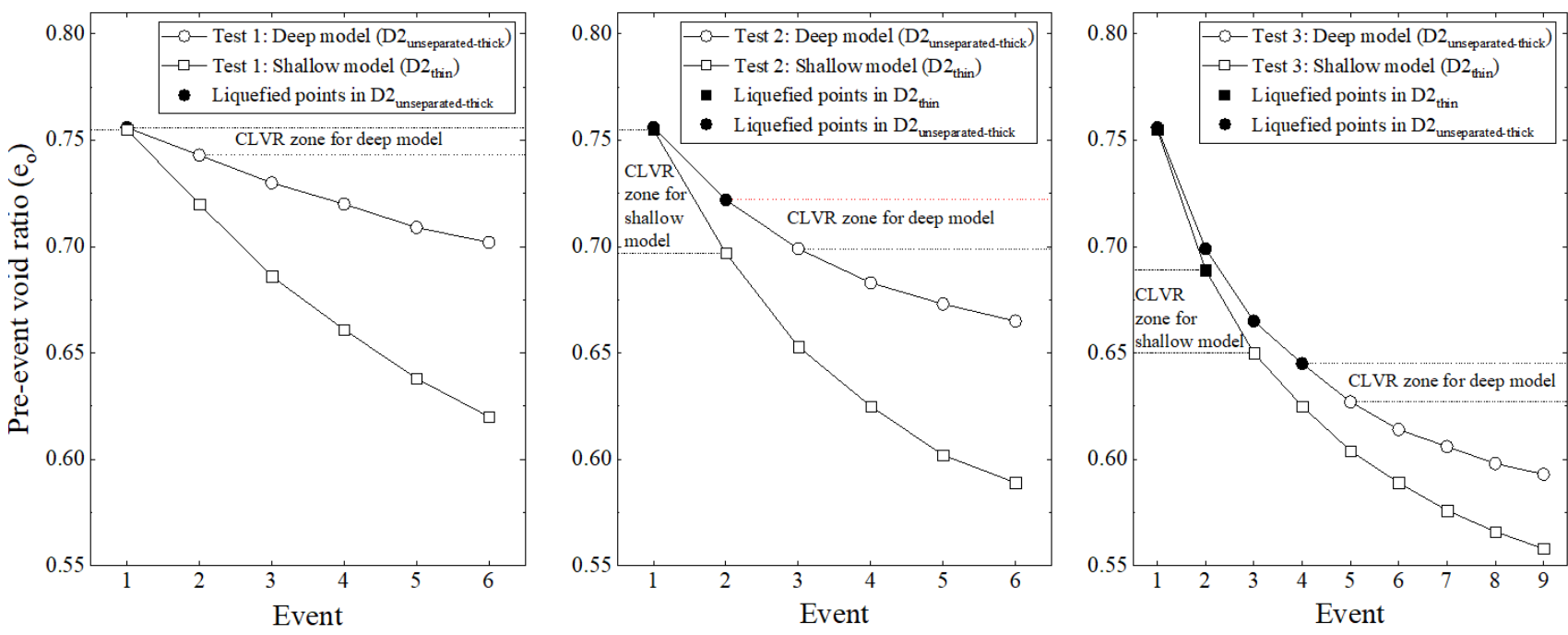

Figure 14: Pre-event void ratio in all shaking events

words, the CLVR of sand is lower for earthquake-induced with larger PGA and vice versa; (2) CLVR is depth dependent i.e. the CLVR of sand is lower for the shallower section in comparison to sand layer with same thickness at deeper positions.

\section{Conclusion}

Successive shaking table experiment with varying depth of sand model, peak ground acceleration, and shaking duration of input motion were conducted to examine the multiple liquefaction phenomenon in layered sand via its excess pore water pressure ratio, and the following main conclusions have been derived: (1) The re-liquefaction phenomenon is influenced by the depth of sand layer and shallower sand layers are highly susceptible to multiple liquefaction in comparison to the deeper sand layers because the sand particles after the ceasing of input motion sink towards the depth and upper particles fall on it making the top portion comparatively loose. (2) There exists a critical liquefaction void ratio within a zone with which we can forecast the presence or absence of re-liquefaction in the next earthquake. However, critical liquefaction void ratio is dependent on depth of sand model and peak ground acceleration of the earthquake. Sand model is susceptible to re-liquefy if the void ratio before the earthquake is larger than critical liquefaction void ratio. (3) Shaking duration of input motion plays an important factor that can govern the number of times sand re-liquefies. In a shorter duration earthquake, the sandy ground will re-liquefy several times, and this number decreases if the shaking duration is larger.

\section{References}

K Arulandan and J Sybico Jr. Post-liquefaction settlement of sands. In Predictive soil mechanics: Proceedings of the Wroth Memorial Symposium held at St Catherine's College, Oxford, 27-29 July 1992, pages 94-110. Thomas Telford Publishing, 1992.

Peyman Ayoubi and Ali Pak. Liquefaction-induced settlement of shallow foundations on two-layered subsoil strata. Soil Dynamics and Earthquake Engineering, 94:35-46, 2017.

Dikshit Babu Nepal, Jianliang Deng, Jinjian Chen, and Tshegofatso Maakoe. Re-liquefaction of sand in shaking table. $M S \& E, 758(1): 012050,2020$.

Nurhan Ecemis. Simulation of seismic liquefaction: 1-g model testing system and shaking table tests. European journal of environmental and civil engineering, 17(10):899-919, 2013.

Ik-Soo Ha, Scott M Olson, Min-Woo Seo, and Myoung-Mo Kim. Evaluation of reliquefaction resistance using shaking table tests. Soil dynamics and earthquake engineering, 31(4):682-691, 2011.

Yu Huang and Miao Yu. Review of soil liquefaction characteristics during major earthquakes of the twenty-first century. Natural hazards, 65(3):23752384, 2013.

Kenji Ishihara and Shigeru Okada. Effects of stress history on cyclic behavior of sand. Soils and Foundations, 18(4):31-45, 1978. 
Eiichi Kuribayashi and Fumio Tatsuoka. Brief review of liquefaction during earthquakes in japan. Soils and Foundations, 15(4):81-92, 1975.

Richard S Ladd. Specimen preparation and cyclic stability of sands. Journal of Geotechnical and Geoenvironmental Engineering, 103(ASCE 13014 Proceeding), 1977.

J Paul Mulilis, Kandiah Arulanandan, James K Mitchell, Clarence K Chan, and H Bolton Seed. Effects of sample preparation on sand liquefaction. Journal of the Geotechnical Engineering Division, 103(2):91-108, 1977.

Scott M Olson, Russell A Green, and Stephen F Obermeier. Geotechnical analysis of paleoseismic shaking using liquefaction features: a major updating. Engineering Geology, 76(3-4):235-261, 2005.

G Papathanassiou, Sp Pavlides, B Christaras, and $\mathrm{K}$ Pitilakis. Liquefaction case histories and empirical relations of earthquake magnitude versus distance from the broader aegean region. Journal of Geodynamics, 40(2-3):257-278, 2005.

John D Sims and Cristofer D Garvin. Recurrent liquefaction induced by the 1989 loma prieta earthquake and 1990 and 1991 aftershocks: implications for paleoseismicity studies. Bulletin of the Seismological Society of America, 85(1):51-65, 1995.

Teruyuki Suzuki and Shosuke Toki. Effects of preshearing on liquefaction characteristics of saturated sand subjected to cyclic loading. Soils and foundations, 24(2):16-28, 1984.

Ikuo Tohno and Yasuhiro Shamoto. Liquefaction damage to the ground during the 1983 nihonkai- chubu (japan sea) earthquake in aomori prefecture, tohoku, japan. Natural Disaster Science, 8(1):85116, 1986.

Hirofumi Toyota and Susumu Takada. Variation of liquefaction strength induced by monotonic and cyclic loading histories. Journal of geotechnical and geoenvironmental engineering, 143(4):04016120, 2017.

H Tsuchida. Prediction and countermeasure against the liquefaction in sand deposits. In Abstract of the seminar in the Port and Harbor Research Institute, pages 31-333, 1970.

Kazue Wakamatsu. Recurrent liquefaction induced by the 2011 great east japan earthquake. Journal of Japan Association for Earthquake Engineering, 12 (5):69-88, 2012.

Susumu Yasuda and Ikuo Tohno. Sites of reliquefaction caused by the 1983 nihonkai-chubu earthquake. Soils and Foundations, 28(2):61-72, 1988.

Bin Ye and Hailong Hu. Investigation on the reliquefaction behaviors of sand using shaking table tests. In GeoShanghai International Conference, pages 300-307. Springer, 2018.

Bin Ye, Hailong $\mathrm{Hu}$, Xiaohua Bao, and Ping Lu. Reliquefaction behavior of sand and its mesoscopic mechanism. Soil Dynamics and Earthquake Engineering, 114:12-21, 2018.

$\mathrm{T}$ Leslie Youd and Seena $\mathrm{N}$ Hoose. Historic ground failures in northern California triggered by earthquakes, volume 993. US Govt. Print. Off., 1978. 
